\title{
Women's education and fertility transition in sub-Saharan Africa
}

\author{
David Shapiro*
}

\begin{abstract}
Sub-Saharan Africa was the last major part of the developing world to experience fertility decline, and fertility in the region remains high compared to fertility in Asia and Latin America. Correspondingly, women's education, known to be an important factor related to fertility via multiple pathways, is comparatively low in the region. Numerous studies have documented the importance of increasing women's education as a key variable contributing to fertility decline in the developing world. This paper uses aggregated data to examine the role of increasing women's educational attainment in the ongoing fertility transition in sub-Saharan Africa, in conjunction with other socioeconomic changes such as declining infant and child mortality and changes in economic well-being. In addition, detailed patterns of fertility differences by educational attainment are also examined across countries using individual-level data, highlighting the significant role in fertility transition of increasing secondary and higher education.
\end{abstract}

\section{Introduction}

Sub-Saharan Africa was the last major part of the developing world to experience fertility decline, and fertility in the region remains still quite high compared to fertility in Asia and Latin America (United Nations 2011). In addition, fertility transition in sub-Saharan Africa has been characterised by stalling in a number of countries, and to a greater degree than elsewhere in the third world (Bongaarts 2005, 2008; Westoff and Cross 2005; Shapiro and Gebreselassie 2010; Shapiro et al. 2013). While there is evidence in the literature that some of these apparent stalls may be spurious (Schoumaker 2009; Machiyama 2010), it does appear that the pace of fertility is distinctly slower in sub-Saharan Africa than elsewhere in the developing world (Bongaarts 2008; Shapiro et al. 2013).

\footnotetext{
* David Shapiro, Department of Economics, Pennsylvania State University, University Park, PA 16802 USA. Email: dshapiro@psu.edu
} 
Women's education has long been known to be an important factor related to fertility via multiple pathways (Cochrane 1979), from delaying the onset of childbearing to reducing the desired number of children to more effective control of fertility, among other aspects. Bongaarts (2010) has recently examined the causes of educational differences in fertility in sub-Saharan Africa, and his analysis emphasised educational differences in desired family size as well as in demand for, use, and effectiveness of contraception.

Numerous studies have documented the importance of increasing women's education as a key variable contributing to fertility decline in the developing world (see, for example, Jejeebhoy 1995; Rutstein 2002; Bongaarts 2008, 2010; Shapiro and Gebreselassie 2008, 2010; Shapiro et al. 2013). And while over the long haul women's educational attainment has been increasing in sub-Saharan Africa as it has in other developing countries (Schultz 1993), Africa shows distinctly lower levels of women's schooling compared to Asia and Latin America (United Nations 2010).

This paper seeks to add to the literature on fertility transition in sub-Saharan Africa. That literature includes excellent overview studies by Cohen (1998) and Garenne and Joseph (2002). The latter in particular emphasises the importance of analysing rural and urban populations separately, a theme in Shapiro and Tambashe (2002) as well. Here, however, the emphasis is on women's education as a key factor for the progress of fertility transition in the region.

The paper examines the contribution of increasing women's education to the ongoing fertility transition in sub-Saharan Africa, utilising multiple approaches. The theoretical framework that underlies the approach in the paper is the Easterlin framework for fertility analysis (Easterlin 1975; Easterlin and Crimmins 1985). This flexible approach with an economic base that is at the same time oriented to accommodating perspectives from other disciplines is the theoretical focus that was used early on by the National Academy of Sciences in a major study of determinants of fertility in developing countries (Bulatao et al. 1983). It underlies my own work on fertility and fertility transition going back two decades, as well as work by many other scholars.

The first substantive section of the paper provides a descriptive overview of fertility transition in the developing world so as to put fertility in sub-Saharan Africa in a comparative perspective. Fertility transition within the different subregions of sub-Saharan Africa is also reviewed. Similarly, the paper gives comparative data on women's education in sub-Saharan Africa, Asia, and Latin America and the Caribbean. Current and recent data on women's education and fertility at the national level within sub-Saharan Africa are presented subsequently. The data in this first section, at regional, sub-regional and national levels, show very clearly the strong inverse relationship between fertility and women's education.

The remaining substantive sections of the paper provide multivariate analyses of fertility behaviour that explore the importance of education in fertility 
transition more fully. The first of these two sections uses aggregated data to examine the contribution of increasing women's educational attainment to the ongoing fertility transition in sub-Saharan Africa. This part of the paper also looks at the influence on fertility decline of other socioeconomic changes such as declining infant and child mortality and changes in overall economic well-being, as measured by growth in real GDP per capita (as in Shapiro and Gebreselassie 2008, 2010, and Shapiro et al. 2013).

The data analysed are from the Demographic and Health Surveys (DHS). The analyses of aggregated data examine data at three levels for each country with at least two DHS surveys: national, urban-rural and regional (regions within each country). This essentially entails an updating of the analyses in Shapiro and Gebreselassie $(2008,2010)$ for which the most recent data were from 2007. Data are now available up through 2010 , and include surveys where previous fertility stalls appear to have reversed (e.g. Ghana and Kenya).

In addition, expanding on recent work by Frankenfield (2011), the concluding substantive section of the paper analyses individual-level DHS data from numerous sub-Saharan countries to determine patterns of fertility differences by educational attainment. Following up on discussions in the literature regarding what happens to fertility differentials by education during the course of fertility transition (see Castro Martin 1995; Cleland 2002; Bongaarts 2003), we also look at whether these patterns vary according to the general level of fertility, so as to assess the degree to which these differentials change systematically in subSaharan Africa as fertility transition unfolds.

Further, following the approach in Shapiro and Tambashe (2003), these analyses of individual data differentiate educational attainment more finely than the typical "none/primary/secondary-and-higher" trichotomy found in DHS reports or the Measure DHS STATcompiler and often used in examining women's educational attainment and fertility. In particular, this finer differentiation, which disaggregates what for the most part is the secondary-andhigher group, allows one to see that fertility differences by educational attainment tend to widen as one moves from lower-level to upper-level secondary schooling and again to post-secondary education. This widening is often substantial, and it has important implications for the future of fertility transition in the region implications that are masked by use of the trichotomy noted above.

The final section of the paper summarises the empirical findings and discusses their implications for the future of fertility transition in sub-Saharan Africa. 


\section{Fertility transition and women's education in the developing world}

As a starting point, it is useful to briefly review fertility transition in the developing world. Figure 1 shows United Nations (2011) estimates and projections of total fertility rates (TFRs) for sub-Saharan Africa, Northern Africa, Asia, and Latin America and the Caribbean, for the period from 1950-2050. The onset of fertility transition in the developing world during the second half of the 20th century is evident, as is the fact that fertility transition in sub-Saharan Africa did not emerge until well after its onset elsewhere in the third world. As a consequence of this late start, it is not surprising to note that the estimated TFRs for 2010-2015 are between 2 and 3 for Northern Africa, Asia, and Latin America and the Caribbean, as compared to an estimate that is not much below 5 for subSaharan Africa.

Figure 1:

Total fertility, by region, 1950-2050

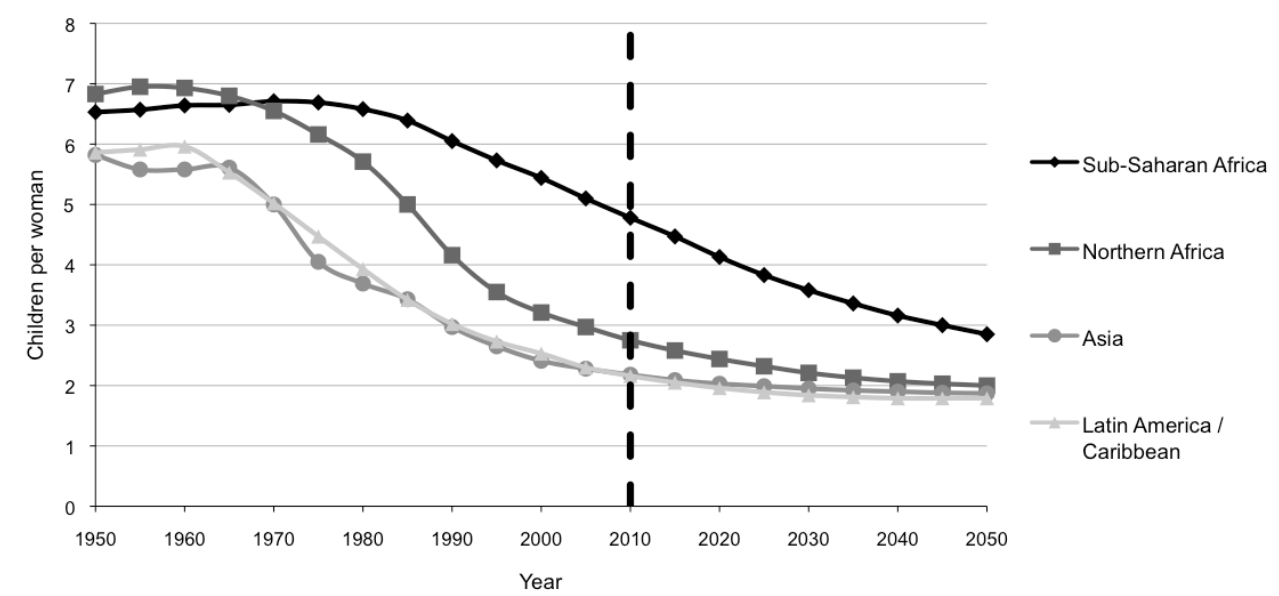

Source: Population Division of the Department of Economics and Social Affairs of the United Nations Secretariat, World Population Prospects: The 2010 Revision, http//esa.un.org/unpd/wpp/index.htm

Estimated fertility rates from the United Nations for sub-Saharan Africa and its component sub-regions are shown in Figure 2. Southern Africa, dominated by South Africa, stands out as the one sub-region where fertility decline began early, and where fertility has fallen to levels comparable to those prevailing elsewhere in the developing world. The other three sub-regions manifest the later onset of fertility decline evident for the region as a whole, with Middle Africa showing the highest fertility for most of the past 25 years. With respect to these fertility 
differences by sub-region, it is worth noting that various measures of women's education, such as primary and secondary enrolment rates and the percentage of adult women who are illiterate, indicate that Southern Africa has the highest women's education and Middle Africa has the lowest (United Nations 2010).

\section{Figure 2:}

Total fertility, sub-Saharan Africa and its sub-regions, 1950-2050

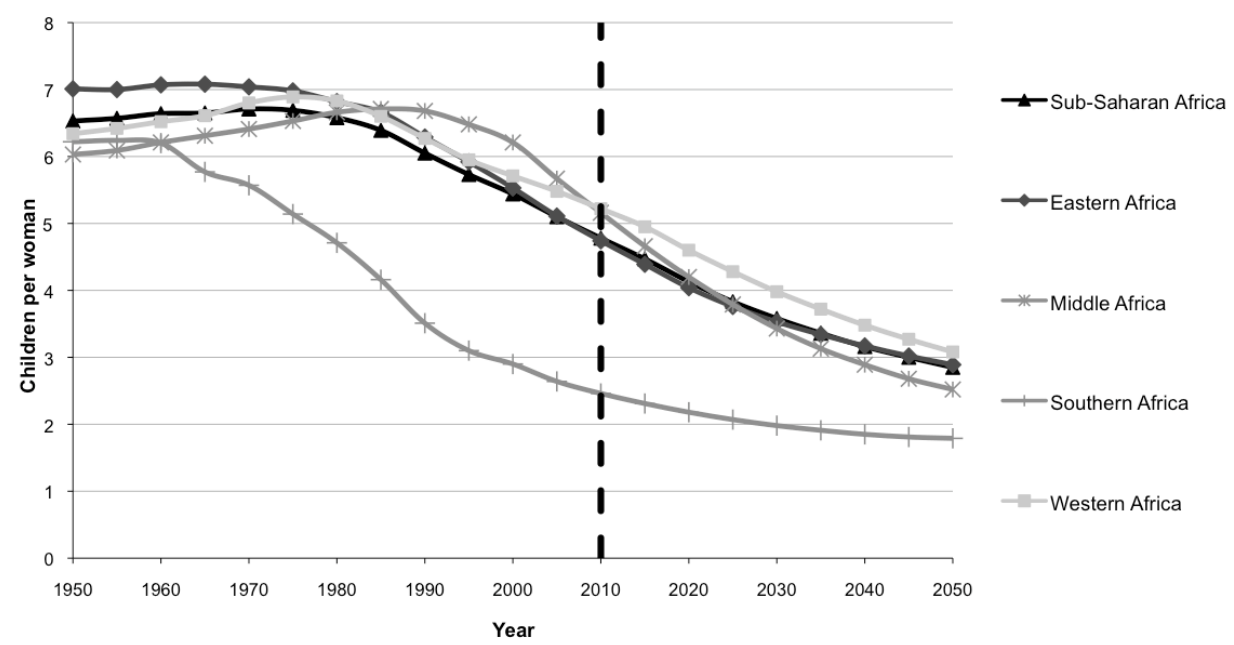

Source: Population Division of the Department of Economics and Social Affairs of the United Nations Secretariat, World Population Prospects: The 2010 Revision, http//esa.un.org/unpd/wpp/index.htm

More broadly, recent data from the United Nations (2010: Fig. 3.6) on women's educational attainment for those aged 25 and over are shown in Figure 3 for sub-Saharan Africa (SSA), Asia, and Latin America and the Caribbean (LAC). The comparatively low schooling of women in sub-Saharan Africa is obvious: more than 40 per cent of adult African women have no schooling at all, compared to fewer than 20 per cent of women in Asia and just over 10 per cent of those in LAC. Conversely, while 35 per cent of women in Asia and LAC have been to secondary school, the corresponding figure is only about half that percentage among African women, and likewise, exposure to tertiary education is very low among women from sub-Saharan Africa and substantially higher among women from the other two regions. 
Figure 3:

Highest level of education attained, by region, women aged $25+$ (percentages)

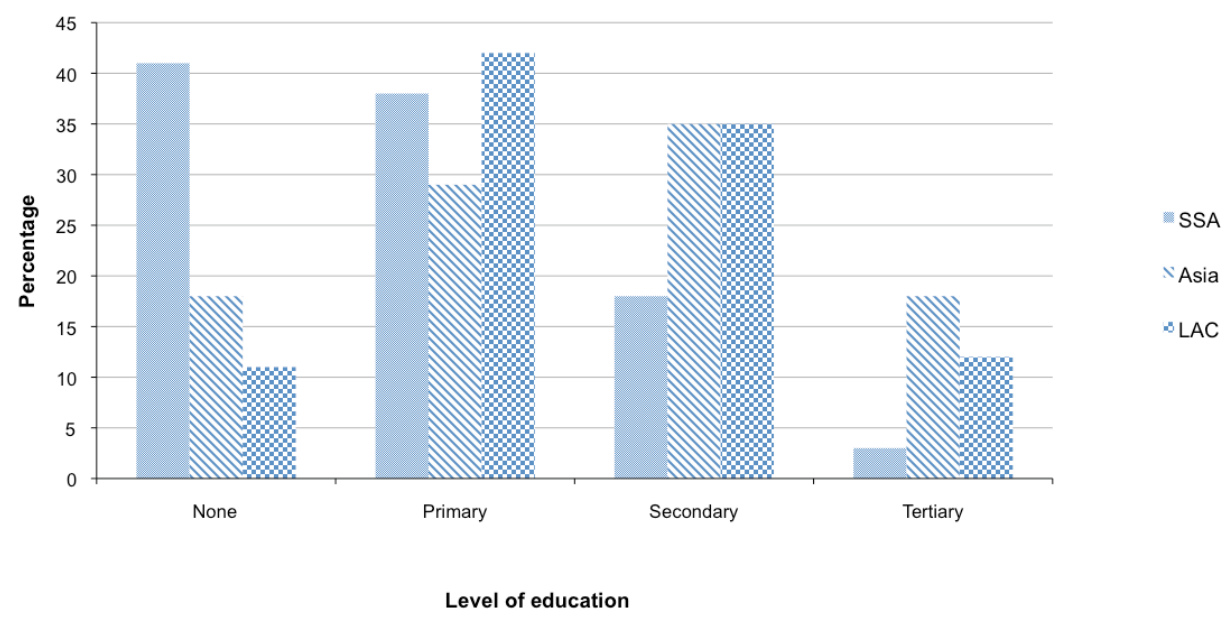

Source: United Nations 2010: Figure 3.6.

At this highly aggregated level of major regions, then, it is clear that there is a broad negative association between women's educational attainment and their fertility. This inverse relationship is apparent as well if we confine our examination to individual countries within sub-Saharan Africa. Figure 4 is a scatter plot of national-level DHS data on fertility and women's education from the most recent surveys in each of 28 sub-Saharan countries (limited to surveys carried out in 2000 and later). There is considerable variation in both fertility and women's educational attainment: the (unweighted) average TFR is just under 5.3, with a range from 3.3 (Lesotho) to 7.0 (Niger), and the average number of years of schooling of women of reproductive age equals 4.6, with even greater variation than in the case of fertility - a range from just under 1 (Niger) to 8.4 (Namibia).

The inverse relationship between these two variables is apparent from the graph. In addition, a simple regression of the TFR on the average number of years of schooling yields a highly significant negative coefficient for schooling of nearly -0.3 , and given the strong negative correlation between these two variables in excess of 0.7 in absolute value, this variable alone accounts for just over half of the TFR variation across countries. ${ }^{1}$

1 There is a clear tendency for the countries at the high end of women's schooling to have especially low fertility (below the regression line), and the four countries that fit this description are Lesotho, Namibia, Swaziland and Zimbabwe- three from southern Africa and Zimbabwe from southern east Africa. Indeed, a simple regression substituting average schooling squared for average schooling yields a highly significant negative coefficient and has somewhat greater explanatory power than the simple linear version reported above, suggesting that fertility decline in the region accelerates with increased educational attainment. 
Whether we consider highly aggregated data at the level of major world regions or country-specific data, examination of the relationships between women's education and fertility shows strong negative associations. The following section moves from this examination of levels of fertility and education at a point in time to an analysis of within-country changes in fertility over time, exploiting the wealth of data and multiple surveys of individual countries that have been carried out since the mid-1980s by the Demographic and Health Surveys program. ${ }^{2}$

Figure 4:

Total fertility rates and average number of years of schooling, women aged 15-49, sub-Saharan Africa

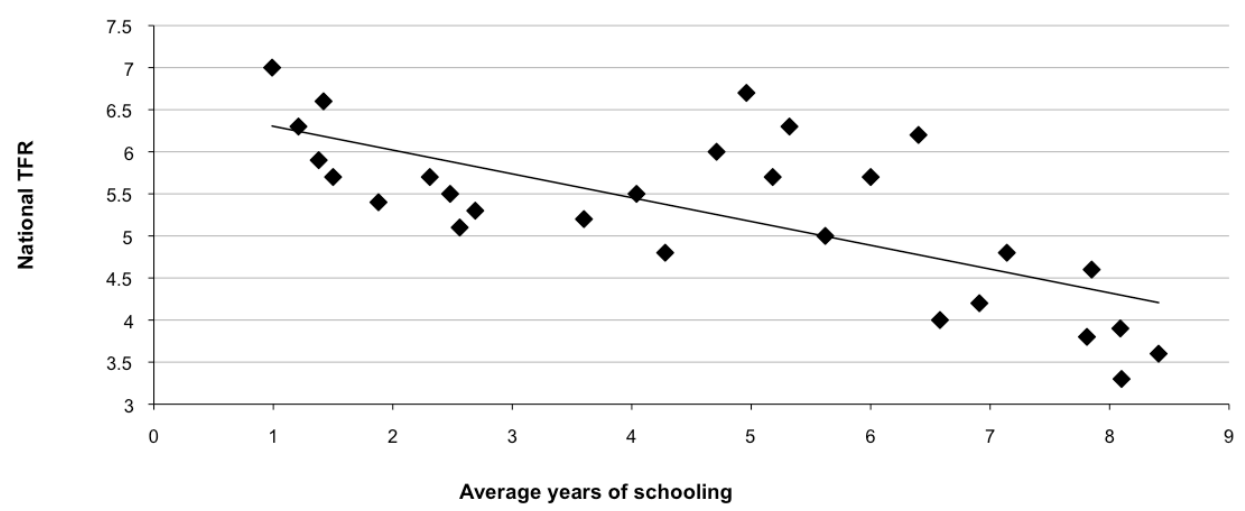

Source: Calculated from DHS data for the 28 sub-Saharan nations that have had their most recent DHS in 2000 or later.

\section{Education and other factors influencing fertility declines}

There are 25 countries in sub-Saharan Africa that have data available for multiple Demographic and Health Surveys, and the analyses in this section examine the declines in fertility between consecutive surveys in these countries, relating said declines to the (absolute) changes in women's educational attainment and in other factors that are presumed to influence the pace of fertility decline. We use all available surveys. ${ }^{3}$ The countries for which data have been analysed account for nearly three-quarters of the population of sub-Saharan Africa. This section, then,

For detailed information on the DHS Program, see http://www.measuredhs.com/.

3 There is one exception here: the 1999 DHS for Nigeria. Concerns about data reliability regarding the measurement of fertility prompted us to exclude results from that survey. See Ibisomi (2007) for analysis of problems with the Nigeria 1999 DHS fertility data. 
reports results of analyses of changes in fertility, using pairs of consecutive DHS surveys as the unit of analysis. ${ }^{4}$ These analyses of aggregated data regress (absolute) declines in fertility from one DHS survey to the next on changes between the two surveys in several variables that both the Easterlin framework for fertility analysis and extensive prior empirical work on fertility transition suggest should be relevant to fertility decline.

More specifically, fertility declines between surveys are regressed on changes in the educational attainment of women, in the infant and child mortality rate, in real GDP per capita and in use of modern contraception, as well as on a time trend. For this analysis, then, we use first differences between pairs of consecutive cross-sectional data points from surveys in each country. The differencing eliminates time-constant effects from the estimated model. The empirical model treats unobserved differences between countries as a set of fixed parameters that can be partialled out of the estimating equations. Furthermore, the regression model with first-differenced data explicitly considers how changes in the explanatory variables over time affect the change in the dependent variable over time.

There is an econometric issue that arises in these analyses, however. Since countries with three or more DHSs will have more than one observation (i.e. there will be two pairs of surveys for countries with three DHSs, three pairs of surveys for countries with four DHSs, etc.), these data are not independent and there may be correlated observations. The Generalised Estimating Equations (GEE) method is a technique that can be used to account for the lack of independence among observations in generalised linear regression models (Liang and Zeger 1986; Zeger and Liang 1986; Diggle et al. 1994). Hence, we use the GEE method for the analyses in this part of the paper.

As noted earlier, we have used this approach in previous analyses of fertility transitions, both in sub-Saharan Africa (Shapiro and Gebreselassie 2008, 2010) and in the developing world more broadly (Shapiro et al. 2013). As in the earlier analyses, we report results for three different levels of analysis: national data, data separately for urban and rural places, and regional-level data (for regions within each country). ${ }^{5}$

Table 1 reports the results of these analyses. Consider the first column of estimated coefficients, for national-level data. We have two explanatory variables measuring the changes between surveys in the educational attainment of women of reproductive age: one showing the increase in the percentage of women with

4 For example, Benin, with surveys in 1996, 2001 and 2006, contributes two observations to our analyses here-one pertaining to changes between 1996 and 2001, and the second examining the changes between 2001 and 2006. In total, there are 55 pairs of consecutive surveys available for the 25 countries covered by these surveys.

5 Analyses for data separately by urban and rural residence as well as by region also use the GEE method to take account of the lack of independence among observations from the same country. 
no schooling, and the other showing the increase in the percentage of women with secondary or higher education. These two variables reflect different aspects of the educational distribution of women of reproductive age, and as we shall see shortly, each tends to be significantly related to the magnitude of fertility declines.

Table 1:

Regression analyses of the decline in the total fertility rate between pairs of surveys, national, urban/rural and regional data

\begin{tabular}{llll}
\hline Variable & National & Urban/rural & Regional \\
\hline $\begin{array}{l}\text { Increase in percentage of women with no } \\
\text { schooling }\end{array}$ & $-0.0330^{* *}$ & $-0.0379^{* *}$ & $-0.0378^{* *}$ \\
$\begin{array}{l}\text { Increase in percentage of women with at least } \\
\text { secondary education }\end{array}$ & $0.0141^{*}$ & $0.0125^{* *}$ & $0.0099^{*}$ \\
$\begin{array}{l}\text { Increase in infant and child mortality } \\
\text { Annual percentage growth in GDP/head, last 5 }\end{array}$ & $-0.0059^{* *}$ & $-0.0031^{+}$ & $-0.0046^{* *}$ \\
$\begin{array}{l}\text { years (three-year lag) } \\
\text { Growth in the percentage of women using }\end{array}$ & $-0.0270^{+}$ & -0.0196 & $-0.0311^{* *}$ \\
$\begin{array}{l}\text { modern contraception } \\
\text { Time trend }\end{array}$ & 0.0086 & $0.0202^{* *}$ & 0.0031 \\
Intercept & $-0.0306^{* *}$ & $-0.0366^{* *}$ & $-0.0361^{* *}$ \\
\hline $\begin{array}{l}\text { Wald chi-square } \\
\text { Sample size }\end{array}$ & $0.2949^{* *}$ & $0.3759^{* *}$ & $0.3892^{* *}$ \\
\hline
\end{tabular}

Notes: ${ }^{a}$ For the national level, we measure the change in infant mortality with a lag of 0-14 years; for the other two levels, the lag is 0-9 years; ** Significant at the .01 level;* Significant at the .05 level; + Significant at the .10 level. Estimated via Generalized Estimating Equations (GEE) Method

Given the secular increase in women's education, the increase in the percentage of women with no schooling is typically negative (the mean of this variable is -5.1), while the increase in the percentage of women with secondary or higher education is usually positive (the mean value is +5.0 ). The significant negative coefficient of the first of these variables tells us that those countries which experience larger declines in the percentage of women with no schooling tend to experience more rapid declines in the national total fertility rate. Likewise, the significant positive coefficient for the variable measuring the increase in the percentage of women with secondary or higher education indicates that countries with more rapid growth in women's schooling at the upper end of the schooling distribution experience larger declines in their total fertility rate, other things equal. The national-level data thus indicate that more rapid progress in increasing women's schooling indeed contributes to more rapid fertility decline.

In order to get an idea of the potential magnitude of the contribution of changing women's education to fertility decline in sub-Saharan Africa, it is of interest to consider the implications of comparatively large improvements in women's education for fertility decline. For the entire sample, the mean value of the decline in the TFR between successive surveys is 0.349 . The coefficients in 
the first column of Table 1 imply, however, that if a country were able to realise a decline in the percentage of women with no schooling that is one standard deviation bigger than the average decrease (representing a decline of 9.8 percentage points rather than 5.1), this would reduce the TFR by almost 0.16 , other things equal. Correspondingly, if secondary and higher education were to increase by one standard deviation above the mean (i.e., by 11.6 percentage points rather than 5.0 points), the implied additional decline in the TFR would exceed 0.09 , other things equal. The two changes together imply an additional reduction in the TFR of essentially 0.25 , representing more than 70 per cent of the observed average TFR decline between surveys. Clearly, then, these results suggest that more rapid increases in women's education have the potential to substantially accelerate fertility transition in the region.

Consider now the remaining coefficients in the national-level equation. As we have found previously, changes in infant and child mortality are significantly related to fertility declines. The mortality variable measures increases in infant and child mortality over the period 0-14 years prior to each survey, so given the secular decline in infant and child mortality, the mean of the variable is negative (-19 per thousand). Hence, the negative coefficient of the mortality variable implies that countries experiencing larger declines in mortality over the past 15 years tend as well to manifest larger declines in fertility. ${ }^{6}$ If mortality reduction were one standard deviation greater than the mean, the implied fertility decline would be more than 0.13 greater, representing almost 40 per cent of the average fertility decline in the data.

Improvements in women's educational attainment and reductions in infant and child mortality constitute important socioeconomic changes. Likewise, growth in economic well-being is an additional form of socioeconomic change. We have found previously that, contrary to the historical decline of fertility in the West, which was associated with increased levels of economic well-being, DHS data from the mid-1980s onward suggest that fertility decline in both sub-Saharan Africa and in the developing world on the whole appears to be slower when economic growth is more rapid (Shapiro and Gebreselassie 2010; Shapiro et al. 2013). This is consistent with suggestions from the literature that in sub-Saharan Africa, fertility decline may be prompted by economic crisis (see, for example, Lesthaeghe 1989; National Research Council 1993; Eloundou-Enyegue et al. 2000). In any case, here we find a negative and weakly significant coefficient on the variable measuring lagged growth in real GDP per capita as well.

6 Given that improved women's education is typically associated with lower infant and child mortality, inclusion of the mortality variable in the equation tends to bias downward the overall effect of women's education on fertility. Indeed, if the mortality variable is excluded from the equation, the absolute values of the education coefficients increase a bit. However, reflecting the underlying Easterlin conceptual framework, we have left the mortality variable in this and subsequent equations in order to highlight the importance of declining mortality as a factor contributing directly to fertility transition. 
Growth in the use of modern contraception was hypothesised to contribute to more rapid fertility decline, other things equal. However, while the estimated coefficient for this variable was positive, it was not statistically significant at the national level. ${ }^{7}$

Finally, we also included a time trend variable, since in previous work we had determined that, other things equal, fertility declines tended to diminish in magnitude over time (Shapiro and Gebreselassie 2010; Shapiro et al. 2013). The result was a highly significant negative coefficient. One possible explanation for this result can be found in the argument that as fertility declines in the region began from quite high levels, earlier declines will be larger than later ones, and the time trend may be picking up this effect. However, when we added a variable representing the initial level of fertility in the pair of surveys, that variable was not statistically significant, and the size and significance of the coefficient of the time trend variable were essentially unaffected.

All told, the explanatory variables in the first equation in Table 1 are important in accounting for the variation in fertility declines, ${ }^{8}$ and clearly, declining infant and child mortality as well as increased women's educational attainment are especially pertinent explanatory factors. As indicated by the brief discussion above concerning the quantitative implications of increasing women's education, however, this is evidently a key factor in the ongoing process of fertility transition in sub-Saharan Africa.

The second column of coefficients reports results of similar analyses, but with two observations for each pair of surveys - one for urban places and the other for rural places. Again, the two education variables are both statistically significantly related to fertility decline. The absolute value of the coefficient for the increase in the percentage of women with no schooling is a bit larger here than for the national-level estimate, while the coefficient for the increase in the percentage of women with secondary or higher schooling is slightly smaller. Broadly speaking, the magnitudes of the estimated coefficients are reasonably similar to those estimated at the national level.

The change in infant and child mortality is again related to the pace of fertility decline, although the coefficient is only weakly significant and the absolute value of the coefficient is considerably smaller than the corresponding national-level coefficient. ${ }^{9}$ This second regression does find a significant effect of increased use

7 As with reductions in infant and child mortality, increased use of modern contraception is likely to be linked to improvements in women's educational attainment.

8 In an Ordinary Least Squares version of the equation, in which the magnitudes and significance of the coefficients were quite similar to those in the GEE version, the R-square value approached 0.5 -i.e. the explanatory variables accounted for nearly half of the variation in fertility declines across pairs of surveys.

9 The mortality variable here and for the regional-level estimates is measured using a lag of 0-9 years rather than the $0-14$ year lag used for the national level, because of the more limited data provided at the subnational levels. 
of modern contraception that contributes to more rapid fertility decline, and as in the previous equation there is a significant negative coefficient for the time trend variable, with a somewhat larger coefficient in absolute value. There is again a negative coefficient for GDP growth, but it is not statistically significant.

A variant of this second equation was also estimated adding a dummy variable for urban places. That variable had a positive and significant coefficient on the order of 0.2 , indicating that, other things equal, fertility decline is proceeding at a more rapid pace in urban places than in rural places. Addition of that variable did not alter the significance of any of the other variables, and typically changed their magnitudes only modestly.

The last set of estimates in Table 1 is based on data at the regional level within each country. As was the case at the national and urban/rural levels, both of the education variables are statistically significant, and the magnitudes of the estimated coefficients are pretty similar to those estimated earlier (a bit lower for the variable indicating the change in secondary and higher schooling). Likewise, the mortality variable and the time trend are significantly related to the magnitude of fertility decline, other things equal, as was the case earlier. And GDP growth now has a highly significant negative coefficient. By contrast, the contraception variable is not significant.

These analyses of aggregated data, then, show that increased women's educational attainment, changes in infant and child mortality, and the time trend are the variables that are consistently associated with fertility decline between surveys. There is some evidence that growth in real per capita GDP slows fertility decline, while increased use of modern contraception contributes to fertility declines.

In addition, we have seen that as compared to a country with average values of all of the explanatory variables, including our two education measures, a country where women make more rapid educational progress as indicated by our two measures would experience substantially larger declines in its TFR. This calculation highlights the importance of improving women's education as a factor contributing to ongoing fertility transition.

\section{Cumulative fertility differences by educational attainment}

In this section we turn from our examination of aggregated data to look at analyses of individual-level data pertaining to education and fertility. The primary objective here is to assess the patterns and magnitudes of fertility differentials by education, using a more detailed classification of educational attainment than is customary. As noted earlier, DHS reports and the Measure DHS STATcompiler ordinarily use a trichotomy to represent women's education, with women classified either as having no schooling, primary education, or secondary and 
higher education. However, as reflected in the data presented earlier in Figure 4, DHS data sets for individual female survey respondents provide data on the number of years of schooling, thereby allowing for more detailed characterisations of women's educational attainment.

In addition, we also seek to determine if there is any pattern of fertility differentials by education in relation to the ongoing process of fertility transition. Castro Martin (1995), in looking at fertility differentials by education among 26 developing countries in Africa, Asia, and Latin America and the Caribbean, finds that "[t]he largest gaps do not correspond to societies at the earliest stages of the fertility transition" (189). She finds this to be the case for several countries in subSaharan Africa, and concludes more generally that " $[t]$ he countries in the midst of their fertility transition display the largest differentials" (190). In her discussion she concludes that

In general, the impact of individual schooling on reproductive behavior is weak in poor, mostly illiterate societies, grows stronger as societies improve their overall education and advance in their fertility transition, and becomes less prominent once a relatively low level of fertility has been reached (Castro Martin 1995: 199).

A similar perspective is provided by John Cleland (2002) who states that

As reproductive decline takes root, fertility differentials by schooling initially tend to widen...Childbearing declines first among the best educated and last among the least well educated. In the later phase of fertility transition, these differentials begin to narrow until convergence is reached at the end of transition (194).

By virtue of his anticipation of convergence, Cleland has a stronger view than that of Castro Martin, and he argues that "... the pronounced links between schooling and fertility are a transient phenomenon" (2002: 194).

In contrast to the view that fertility differentials by education initially widen and then shrink to low levels or nothing, John Bongaarts (2003), in his examination of data from 57 developing countries from all over the world, notes a tendency for the absolute difference in fertility between the lowest and highest education groups (no schooling and secondary and higher, respectively) to decline steadily as the transition proceeds. At the same time, he concludes that "educational differentials in fertility remain substantial in the late and posttransitional stages" (333) and hence does not anticipate convergence as countries reach the end of their fertility transitions. ${ }^{10}$

10 We carried out a replication of the approach used by Bongaarts, including more recent surveys but limiting the data to surveys from sub-Saharan Africa. Our results show a modest decline in going from pre- and early-transitional stages (where the overall TFR exceeds 6) to midtransitional levels (where the overall TFR is below 5). Among mid-transitional countries there is a gap in the TFR between women with no schooling and those with secondary and higher 
The data analysis here is based on DHS data from comparatively recent surveys from numerous countries. In particular, for women in each of the 28 countries in sub-Saharan Africa with a most recent DHS in the year 2000 or later, we examine cumulative fertility (the number of children ever born) as a function of women's schooling and some control variables. ${ }^{11}$ Separate OLS equations are estimated for each country. Women's schooling is represented by a series of dummy variables representing the number of years of education attained by the woman. These dummy variables identify the following groups of women: those with 1-6 years of schooling (for the most part, a primary-school education only), those with 7-8 years of education, women with 9-10 years of schooling, those with 11-12 years of schooling, and women who have 13 or more years of education. The reference category consists of women who did not attend school at all, so the estimated coefficient for each group represents the fertility differential between women in that group and those with no schooling, holding age (and, depending on the equation, other control variables) constant. ${ }^{12}$

Our different estimates shed light on both the sensitivity of these estimated differences to different control variables and whether there is any pattern to these differences in relation to a country's stage in the fertility transition. We have generated three sets of estimates. In the first set, we regress the number of children ever born on the woman's age and age squared (to allow for nonlinearities), and the dummy variables described above. With children ever born as the dependent variable, it is imperative to control for age, since in conjunction with a woman's schooling it reflects her duration of exposure to the risk of bearing children. The fertility differentials estimated via the procedure just described show individual-level differences related to education, holding age constant. As we shall see shortly, these differences tend to widen as one moves through the groups with seven and more years of education.

A second set of estimates adds simply a dummy variable for urban residence to the first set. Families in urban places confront a higher net cost of children than families in rural areas (cf. Becker 1960), and fertility in urban places is typically

education on the order of 2.3-2.4- similar to the corresponding gaps reported by Bongaarts (calculated from his Appendix Table A1).

11 An alternative option would be to examine recent fertility rather than lifetime fertility. However, since an important part of the impact of schooling is a consequence of delays in the onset of childbearing, we examine children ever born.

12 The education categories we use were also used in Shapiro and Tambashe (2003), who found that fertility differences by education tended to widen as one moved to higher levels of schooling among women with at least some secondary education. For educational systems with six years of primary school and six years of secondary school-the bulk of educational systems - the 2nd, 3rd and 4th groups constitute women with low, middle and upper levels of secondary education, and the last group comprises women with post-secondary education. However, there are some systems that differ slightly, with, for example, either seven years of primary schooling (e.g. Zimbabwe) or seven years of secondary schooling (Benin). 
lower than in rural places (see Chackiel and Schkolnik 1996, for evidence from Latin America, and Shapiro and Tambashe 2002, for evidence from sub-Saharan Africa). At the same time, better-educated women are more likely to be found in urban places than in rural areas. From this perspective, the first set of estimates will overstate the impact of education on fertility, attributing to education some of the fertility effect of urban residence.

The third set of estimates adds a variable representing the general level of education within the community of residence of each woman. Kravdal (2002) has shown that the individual-level differences that we seek to estimate here are influenced by community levels of education, with higher general levels of education contributing to lower fertility, even after taking account of the individual's education level. Consequently, the third set of regressions further adds a variable measuring the average number of years of schooling in the sampled cluster to which each woman belongs.

Table 2 summarises the results of these analyses, providing the mean values of the estimated coefficients of the education dummy variables for each of the three sets of estimated equations, along with the means of the estimated coefficients for the urban and cluster education variables. The table reveals a clear pattern of increasingly more negative coefficients as one moves through the different schooling groups.

Table 2:

Fertility differentials by educational attainment*

\begin{tabular}{|c|c|c|c|}
\hline \multirow[b]{2}{*}{$\begin{array}{l}\text { Educational } \\
\text { attainment (years) }\end{array}$} & \multicolumn{2}{|c|}{ Controlling for: } & \multirow[b]{2}{*}{$\begin{array}{c}\text { Age, age squared, urban, } \\
\text { mean cluster education }\end{array}$} \\
\hline & $\begin{array}{l}\text { Age, age } \\
\text { squared }\end{array}$ & $\begin{array}{c}\text { Age, age squared, urban } \\
\text { dummy variable }\end{array}$ & \\
\hline $1-6$ & -0.279 & -0.208 & -0.102 \\
\hline $7-8$ & -0.649 & -0.494 & -0.327 \\
\hline $9-10$ & -1.055 & -0.860 & -0.652 \\
\hline $11-12$ & -1.658 & -1.417 & -1.178 \\
\hline 13 and over & -2.360 & -2.087 & -1.771 \\
\hline Urban & -- & -0.425 & -0.216 \\
\hline Mean cluster education & -- & -- & -0.087 \\
\hline
\end{tabular}

Notes: *Average differential in number of children ever born, relative to women with no schooling, and averages of urban dummy variable and mean cluster education. Universe: Countries with most recent survey in 2000 or later $(n=28)$.

Further, the size of the differentials between adjacent educational groups tends to widen as educational attainment increases. The detailed breakdown of what for the most part is "secondary and higher" into four distinct categories reveals the increasingly strong impact of progressively higher levels of education on fertility. That is, not only do the coefficients become increasingly negative, but the implied fertility differences between adjacent groups widen as the educational level increases. For example, in the first column of average coefficients in the 
table, the average differential in the number of children ever born between women with 7 or 8 years of schooling and those with 9 or 10 years of schooling is approximately 0.4 children, while comparing the 9-10 group to the 11-12 group shows an average differential of 0.6 children and between upper-level secondary (11-12) and primarily university women (13 and over) the differential widens further to 0.7 children. This pattern is apparent for the other two sets of estimates as well, albeit with slightly smaller differences.

The smaller differences with the introduction of additional control variables reflect the fact that, looking across the three columns of numbers, the absolute values of the magnitudes of these mean differentials by educational attainment decline as first urban and then mean cluster education are added. The magnitudes of the declines tend to be greater, absolutely, as educational attainment increases. However, in relative terms, the declines are greater for the lower levels of education. Thus, for example, comparison of the third column with the first column shows that adding urban and mean cluster education reduces (in absolute value) the average coefficient for women with 1-6 years of schooling by about 0.18 , compared to a reduction of 0.59 for women with 13 or more years of education, but these reductions correspond to percentage changes of roughly 63 per cent and 25 per cent, respectively.

Examination of the coefficients from the individual country regressions reveals that the general pattern shown by the means in Table 2 may be found in most of the individual cases as well, and these coefficients are typically statistically significant, especially for the groups with 7 or more years of schooling. For example, in the estimates that control only for age and educational attainment, the pattern of increasingly more negative coefficients as educational attainment rises characterises 25 of the 28 countries. The exceptions, in which there is a positive coefficient for women with 1-6 years of schooling, are Gabon (2000), the Democratic Republic of the Congo (2007), and Uganda (2006). ${ }^{13}$ With the exception of Gabon, which has a very small positive coefficient for women with 7 or 8 years of schooling, all coefficients are negative once the second category (7-8) is reached. When urban residence and then community level of education are taken into account, there are more exceptions in some of the individual country results, with several positive coefficients here and there. However, the general pattern in which, other things equal, longer schooling is linked to lower fertility prevails, particularly beyond what are essentially the primary and low-level secondary educational attainment groups.

The second column of numbers in Table 2 hows that, as suggested above, fertility is lower in urban areas, even after controlling for education and age. While the average value of the implied rural-urban difference in children ever

13 This phenomenon of higher fertility in some countries in sub-Saharan Africa among women with primary schooling as compared to those with no schooling was noted by Castro Martin (1995). 
born is in excess of 0.4 children, there is considerable variation in the individual country estimates, with some countries having a rural-urban differential on the order of 0.1 (Chad, DRC, Rwanda) while others have one of 0.8 or larger (Nigeria, Ethiopia). When mean cluster education is added (Column 3 of the numbers in Table 2), the estimated rural-urban differential is cut in half, while higher community education is indeed associated with somewhat lower fertility, even after controlling for individual-level education.

The final part of our analysis consists of comparing the estimates of fertility differentials by educational attainment among countries at different stages of fertility transition. This allows us to address the arguments of Castro Martin, Cleland and Bongaarts discussed above, in the context of our finer breakdowns of educational attainment.

These comparisons are provided in Table 3. The table essentially disaggregates the results from Table 2 in order to show the magnitudes of the estimated fertility differentials by education in relation to the overall national level of fertility. Hence, Panel a of Table 3shows the averages of the coefficients measuring the fertility differentials for the countries with a TFR greater or equal to 6 , between 5 and 5.9, and below 5, respectively, when only educational attainment and age are taken into consideration. (The cutoffs are arbitrary, but designed to illustrate countries at different stages of fertility transition.) It thus is a disaggregation of the results in the first column of numbers in Table 2. Panels $b$ and $\mathrm{c}$ represent disaggregation of the results in the second and third columns of numbers in Table 2 respectively.

Examination of the three panels in Table 3 shows some evidence of narrowing of fertility differentials between essentially university-educated women and those with no schooling as fertility transition proceeds, and particularly in going from the high-fertility group to the medium-fertility group. However, when looking at the other schooling groups it is apparent that there is considerable variation in what happens to the estimated fertility differentials by education as fertility declines, and if anything, there is a greater tendency towards widening of these differentials rather than narrowing as fertility declines. These different findings confirm the desirability of more finely differentiating women's education for those women in the broad "secondary and higher" group. 
Table 3:

Fertility differentials by educational attainment and by overall fertility level

a. Average differential in number of children ever born, relative to women with no schooling, controlling for age and age squared

\begin{tabular}{lccc}
\hline Educational attainment (years) & $\mathbf{> = 6}$ & TFR & \\
\hline $1-6$ & -0.123 & $\mathbf{5 . 0 - 5 . 9}$ & $<\mathbf{5 . 0}$ \\
$7-8$ & -0.503 & -0.381 & -0.264 \\
$9-10$ & -0.870 & -0.688 & -0.711 \\
$11-12$ & -1.522 & -1.093 & -1.147 \\
13 and over & -2.524 & -1.729 & -1.678 \\
Number of countries & 7 & -2.350 & -2.247 \\
\hline
\end{tabular}

Note: Universe: Countries with most recent survey in 2000 or later $(\mathrm{n}=28)$.

b. Average differential in number of children ever born, relative to women with no schooling, controlling for age and age squared and urban residence

\begin{tabular}{lccc}
\hline & & TFR & \\
Educational attainment (years) & $\mathbf{> = 6}$ & $\mathbf{5 . 0 - 5 . 9}$ & $<\mathbf{5 . 0}$ \\
\hline $1-6$ & -0.066 & -0.268 & -0.239 \\
$7-8$ & -0.389 & -0.462 & -0.618 \\
$9-10$ & -0.715 & -0.842 & -0.998 \\
$11-12$ & -1.336 & -1.431 & -1.464 \\
13 and over & -2.318 & -2.034 & -1.980 \\
\hline
\end{tabular}

c. Average differential in number of children ever born, relative to women with no schooling, controlling for age and age squared, urban residence, and mean cluster education

\begin{tabular}{lccc}
\hline Educational attainment (years) & \multicolumn{3}{c}{ TFR } \\
\hline $1-6$ & $\mathbf{> = 6}$ & $\mathbf{5 . 0 - 5 . 9}$ & $<\mathbf{< . 0}$ \\
$7-8$ & -0.031 & -0.127 & -0.125 \\
$9-10$ & -0.325 & -0.242 & -0.440 \\
$11-12$ & -0.632 & -0.568 & -0.779 \\
13 and over & -1.232 & -1.120 & -1.206 \\
\hline
\end{tabular}

\section{Summary, conclusions and the future of fertility transition in sub-Saharan Africa}

This paper has examined women's education and fertility transition in subSaharan Africa from multiple perspectives. The descriptive overview following the introduction highlights the delay in initiation of fertility transition in subSaharan Africa relative to other parts of the developing world, while also 
documenting the comparatively low levels of educational attainment of adult women in the region. Evidence was also presented indicating that both in the subregions of sub-Saharan Africa as well as at the level of individual countries within the region, places where women's education is greater tend to be places where fertility is lower.

We then analysed aggregated data on changes in fertility (using Demographic and Health Surveys from countries with multiple surveys) to assess the contribution of changes in women's education and other factors to the ongoing fertility transition in the region. These analyses showed clearly that increasing women's education was a very important factor contributing to fertility decline, along with reductions in infant and child mortality. The estimates suggest that countries that are able to realise substantial increases in women's education will correspondingly experience marked declines in fertility. In addition, there was a clear tendency for fertility declines to diminish in magnitude over time, all else being equal.

The third segment of the analyses looked at fertility differentials by educational attainment, with respect to cumulative lifetime fertility (number of children ever born). These differentials were estimated with a finer categorisation of women's schooling than is typically made; most notably, we disaggregated what is most commonly the "secondary and higher" group that is often used in analyses of women's education in developing countries into four sub-groups. The estimated magnitudes of these differentials depended on what additional variables were taken into account besides age, and diminished somewhat as urban residence and the community level of education were controlled for in the analyses. However, the pattern of these differentials was robust across the different estimates: the greater the educational level of a woman, the lower her fertility relative to women with no schooling, and the magnitude of fertility differences between adjacent education groups increased in absolute value as the education level rose. Again, then, the analyses highlighted the importance of education as a key factor influencing fertility, with the implication that improvements in educational attainment will not only contribute to further fertility decline, but may well do so with an increasing impact as the general level of education rises. We also found no clear pattern of changes in fertility differentials by education as fertility transition unfolds.

In attempting to assess the implications of these findings for the future of fertility transition in sub-Saharan Africa, the most obvious point to be made is that the extent of progress in improving women's education will be a key determinant of what happens to fertility. The national-level estimates in the second part of our analyses suggested that a country with a one standard deviation edge over the mean in improvement of each of the two education variables could expect to experience as much as a 70 per cent larger-than-average reduction in its TFR. 
As we saw in the descriptive overview, there is substantial variation across countries in average levels of schooling, and the mean level for the 28 countries we examined was just over 4.5 years. Hence, as women's education continues its long-term rise over time, it will increasingly move into and through the secondary level, where increases in schooling appear to be associated with accelerated declines in fertility. At the same time, however, the analyses of fertility change across surveys found strong evidence that, other things equal, fertility declines tended to diminish over time. If women's education continues to rise and the former of these two effects dominates, then we can anticipate continued reductions in fertility in sub-Saharan Africa, along the lines projected by the United Nations, whose most recent projections (2011) anticipate a TFR for subSaharan Africa of 3.0 by 2050 . However, if whatever factors are responsible for the negative time trend in those analyses of fertility decline persist, and/or continuing improvements in women's education fail to be realised, then it is quite possible that the stalling of fertility transition that has been observed in some countries in the region may become distinctly more prevalent, and the anticipated decline in fertility will not be observed, or may be much slower and smaller than expected.

\section{Acknowledgments}

Revised version of a paper presented at the Wittgenstein Centre Conference on Education and the Global Fertility Transition, Vienna, Austria, November 30 and December 1, 2011. Contributions from Tesfayi Gebreselassie are gratefully acknowledged, as are comments from anonymous reviewers. Excellent research assistance was provided by Nathan Bartell. Funding in support of this research was provided by Bates White, LLC through the "Bates White Research Experience for Undergraduates" program at Penn State University. Responsibility for the contents of the paper rests solely with the author.

\section{References}

Becker, G.S. 1960. „An Economic Analysis of Fertility.“ In Demographic and Economic Change in Developed Countries, ed. Universities-National Bureau of Economic Research, 209-231. New York: Columbia University Press.

Bongaarts, J. 2003. „Completing the Fertility Transition in the Developing World: The Role of Educational Differences and Fertility Preferences." Population Studies (57)3: 321-335.

Bongaarts, J. 2005. „The Causes of Stalling Fertility Transitions.“ Paper presented at the IUSSP International Population Conference, Tours, France, July 2005.

Bongaarts, J. 2008. "Fertility Transitions in Developing Countries: Progress or Stagnation?" Studies in Family Planning (39)2: 105-110. 
Bongaarts, J. 2010. "The causes of educational differences in fertility in Sub-Saharan Africa." Vienna Yearbook of Population Research 2010(8): 31-50.

Bulatao, R.A., R.D. Lee, P.E. Hollerbach and J. Bongaarts, eds. 1983. Determinants of Fertility in Developing Countries. Washington, DC: National Academy Press.

Castro Martin, T. 1995. "Women's Education and Fertility: Results from 26 Demographic and Health Surveys." Studies in Family Planning (26)4: 187-202.

Chackiel, J. and S. Schkolnik. 1996. "Latin America: Overview of the Fertility Transition, 1950-1990.” In The Fertility Transition in Latin America, ed. J. Guzman, S. Singh, G. Rodriguez and E. Pantelides, 3-26. Oxford: Clarendon Press.

Cleland, J. 2002. "Education and Future Fertility Trends, with Special Reference to MidTransitional Countries." In Proceedings of Expert Group Meeting on Completing the Fertility Transition, 187-202. New York: United Nations Population Division.

Cochrane, S.H. 1979. Fertility and Education: What Do We Really Know? Baltimore, MD: Johns Hopkins University Press.

Cohen, B. 1998. "The Emerging Fertility Transition in Sub-Saharan Africa." World Development (26)8: 1431-1461.

Diggle, P.J., K.-Y. Liang and S.L. Zeger. 1994. Analysis of Longitudinal Data. Oxford: Clarendon Press.

Easterlin, R.A. 1975. “An Economic Framework for Fertility Analysis.” Studies in Family Planning (6): 54-63.

Easterlin, R.A. and E:M. Crimmins. 1985. The Fertility Revolution: A Supply-Demand Analysis. Chicago: University of Chicago Press.

Eloundou-Enyegue, P., S. Stokes and G. Cornwell. 2000. "Are There Crisis-Led Fertility Declines? Evidence from Central Cameroon." Population Research and Policy Review (19)1: 47-72.

Frankenfield, D. 2011. "The Fertility Transition in Sub-Saharan Africa: A Three-Country Case Study." Working paper, Department of Economics, Pennsylvania State University.

Garenne, M. and V. Joseph. 2002. "The Timing of the Fertility Transition in Sub-Saharan Africa." World Development (30)10: 1835-1843.

Ibisomi, L.D.G. 2007. „Analysis of Fertility Dynamics in Nigeria: Exploration into Fertility Preference Implementation." PhD diss., University of the Witwatersrand, Johannesburg, South Africa.

Jejeebhoy, S. 1995. Women's Education, Autonomy and Reproductive Behaviour: Experience from Developing Countries. Oxford: Clarendon Press.

Kravdal, O. 2002. "Education and Fertility in Sub-Saharan Africa: Individual and Community Effects. Demography (39)2: 233-250.

Lesthaeghe, R.J. 1989. "Social Organization, Economic Crisis, and the Future of Fertility Control in Africa." In Reproduction and Social Organization in Sub-Saharan Africa, ed. R.J. Lesthaeghe, 475-505. Berkeley and Los Angeles: University of California Press.

Liang, K.-Y. and S.L. Zeger. 1986. "Longitudinal Data Analysis Using Generalized Linear Models." Biometrika Vol. (73): 13-22.

National Research Council, Working Group on Demographic Effects of Economic and Social Reversals. 1993. Demographic Effects of Economic Reversals in Sub-Saharan Africa. Washington, DC: National Academy Press.

Rutstein, S.O. 2002. "Fertility Levels, Trends, and Differentials 1995-1999." DHS Comparative Reports 3. Calverton, Maryland: ORC Macro. 
Schultz, T.P. 1993. "Investments in the Schooling and Health of Women and Men: Quantities and Returns." Journal of Human Resources (28)4: 694-734.

Shapiro, D. and T. Gebreselassie. 2008. "Fertility Transition in Sub-Saharan Africa: Falling and Stalling." African Population Studies (23)1: 3-23.

Shapiro, D. and T. Gebreselassie. 2010. "Falling and Stalling Fertility in Sub-Saharan Africa." Revised version of paper presented at the International Union for the Scientific Study of Population International Seminar on Human Fertility in Africa: Trends in the Last Decade and Prospects for Change, Cape Coast, Ghana, September 16-18, 2008.

Shapiro, D., A. Kreider, C. Varner and M. Sinha. 2013 (forthcoming). "Stalling of Fertility Transitions and Socioeconomic Change in the Developing World: Evidence from the Demographic and Health Surveys." In Ralentissements, résistances et ruptures dans les transitions démographiques. Actes de la Chaire Quetelet 2010, ed. D. Tabutin et al. Louvain-la-Neuve, Belgium: Academia Bruylant/L'Harmattan.

Shapiro, D. and B.O. Tambashe. 2002. "Fertility Transition in Urban and Rural SubSaharan Africa: Preliminary Evidence of a Three-Stage Process." Journal of African Policy Studies (8)2-3: 103-127.

Shapiro, D. and B.O. Tambashe. 2003. Kinshasa in Transition: Women's Education, Employment, and Fertility. Chicago: University of Chicago Press.

United Nations, Department of Economic and Social Affairs. 2010. The World's Women 2010: Trends and Statistics. http://unstats.un.org/unsd/demographic/products/Worldswomen/WW2010pub.htm.

United Nations, Population Division of the Department of Economic and Social Affairs of the United Nations Secretariat. 2011. World Population Prospects: The 2010 Revision. http://esa.un.org/unpd/wpp/index.htm.

Westoff, C.F. and A.R. Cross. 2005. "The Stall in the Fertility Transition in Kenya." Paper presented at the IUSSP International Population Conference, Tours, France, July 2005.

Zeger, S.L. and K.-Y. Liang. 1986. "Longitudinal Data Analysis for Discrete and Continuous Outcomes.” Biometrics (42): 121-130. 